A N N A L E S Annales de Bretagne et des Pays de l'Ouest

Anjou. Maine. Poitou-Charente. Touraine

$121-1 \mid 2014$

Varia

\title{
François Garnier, prisonnier de guerre
}

\section{Yann Lagadec}

\section{OpenEdition}

Journals

Édition électronique

URL : http://journals.openedition.org/abpo/2760

DOI : $10.4000 / a b p o .2760$

ISBN : 978-2-7535-3407-0

ISSN : 2108-6443

Éditeur

Presses universitaires de Rennes

Édition imprimée

Date de publication : 27 mars 2014

Pagination : 205-206

ISBN : 978-2-7535-3405-6

ISSN : 0399-0826

Référence électronique

Yann Lagadec, «François Garnier, prisonnier de guerre ». Annales de Bretagne et des Pays de l'Ouest [En ligne], 121-1 | 2014, mis en ligne le 27 mars 2014, consulté le 23 septembre 2020. URL : http:// journals.openedition.org/abpo/2760 ; DOI : https://doi.org/10.4000/abpo.2760 
PAPE, Louis (éd.), François Garnier, prisonnier de guerre, 1939-1943, Rennes, PUR, coll. " Mémoire commune ", 2013, 130 p.

Dans ce petit ouvrage d'un peu plus de 100 pages, Louis Pape présente, à travers textes, dessins et peintures de son beau-père François Garnier, la captivité de guerre de celui qui, au lendemain du Second Conflit mondial, deviendra professeur à l'École des beaux-arts de Rennes mais se fera aussi connaître comme illustrateur, notamment de la fameuse " méthode Boscher ", du nom de cet instituteur des environs de Loudéac. C'est dire si, bien que vivant avant-guerre au Chesnay, près de Versailles, les liens de Garnier avec la Bretagne sont réels : c'est d'ailleurs à Rennes, chez son grand-père maternel, colonel en retraite, qu'il passa, tout jeune enfant, l'essentiel de la Grande Guerre.

L'on ne peut que se féliciter de la publication de ce livre, illustré de la plupart - à une ou deux exceptions près - des dizaines de dessins et peintures réalisés sur des supports très divers par le jeune peintre, alors étudiant aux beaux-arts de Paris, au cours des 42 mois de guerre et de captivité qui vont de sa mobilisation, en août 1939, à sa libération anticipée, début 1943, ayant réussi à simuler un diabète imposant son retour en France. En effet, si le parcours de François Garnier, mobilisé dans un régiment dijonnais, est a priori assez banal - des escarmouches le long de la frontière franco-allemande à l'automne 1939, en avant de la ligne Maginot, à la retraite désordonnée des mois de mai-juin 1940, de la longue attente en arrière du " front " à l'hiver 1939-1940 à la capture à proximité d'Orléans quelques jours avant la capitulation des armées françaises, de son transfert en Allemagne aux conditions de vie dans le Stalag XVII в ou dans les Kommandos qui en dépendent, en Autriche - le récit pictural qu'il en a indirectement laissé est, lui, beaucoup plus exceptionnel.

Dessins sur feuillets de papier ou sur calque, gouaches, pastels, aquarelles permettent en effet de saisir nombre de détails qui, souvent, échappent aux historiens, soit qu'ils soient difficiles à transmettre par le film ou la photographie, soit que l'on n'ait pas souhaité, alors, y insister. L'ennui, le désœuvrement, la monotonie de la captivité des quelque 2000000 de soldats français pris par les forces du Reich après les durs et meurtriers combats de mai-juin 1940 ressortent ainsi avec force du corpus ici réuni, rappelant combien l'attente fut longue et pénible pour ceux qui, le plus souvent pendant près de cinq années, jusqu'au printemps 1945, n'eurent guère d'espoir de libération. Le courrier, les colis (et les indispensables compléments alimentaires qu'ils apportent), le tabac et le théâtre constituent, dans ces conditions, des " distractions " particulièrement appréciées, ainsi qu'en témoignent quelques dessins mais aussi les lettres de François Garnier. Son témoignage est encore plus fort sans doute sur quelques aspects plus ponctuels : l'humiliation que constitue l'arrivée dans le Stalag VII A de Moosburg, immense camp de transit installé près de Munich, dans lequel les prisonniers sont douchés, rasés, enregistrés; la rencontre des prisonniers de guerre avec des déportés qui n'hésitent pas à passer par le trou des latrines pour pouvoir fumer une cigarette; l'hygiène déplorable qui est celle du Front-Stalag de Pithiviers, à l'été 1940, où les milliers de captifs, sans toilettes, qui doivent de ce fait faire leurs besoins en limite des barbelés, sont rapidement dévorés par la vermine. De ce point de vue, les dessins $n^{\circ} 16,26$ et 27 sont sans doute les plus impressionnants, les plus étonnants.

La déception du lecteur - et de l'historien - n'en est que plus grande en refermant le livre. Si, en effet, l'on dispose désormais, grâce à cette publication, de documents d'une richesse rare, l'absence de véritable analyse historique, de mise en perspective de ces sources exceptionnelles laisse un goût d'inachevé. La bibliographie, limitée aux datés - et orientés - ouvrages d'Henri Amouroux laisse perplexe, d'autant que l'on dispose, sur cette question de la captivité de guerre des Français en 1940-1945, de nombreux travaux qui, de la thèse d'Yves Durand, publiée en 1982 (La captivité. 
Histoire des prisonniers de guerre français, 1939-1945, Paris, FNCPG) ou, du même, de l'ouvrage publié dans la collection "La vie quotidienne " (La vie quotidienne des prisonniers de guerre dans les Stalags, les Oflags et les Kommandos, 1939-1945, Paris, Hachette 1987), aux études plus récentes de Fabien Théofilakis (Anne-Marie PATHE et Fabien TheOFILAKIS, dir., La captivité de guerre au XXe siècle. Des archives, des histoires, des mémoires, Paris, A. Colin, 2012; ou encore, chez l'éditeur des dessins de Garnier : Jean-Claude CATHERINE, dir., La captivité des prisonniers de guerre. Histoire et mémoire, 1939-1945, Rennes, Presses universitaire de Rennes, 2008) auraient permis de mieux mettre en valeur le corpus concernant François Garnier.

Les 25 dessins consacrés par le jeune artiste au Front-Stalag de Pithiviers, particulièrement rares, n'auraient-ils pas, par exemple, gagnés à être confrontés à ce que nous en disent les archives conservées dans le Loiret, émanant de la municipalité de la ville, de la préfecture ou de la presse locale? Plus qu'une notice générale sur les tirailleurs sénégalais (p. 33), dont l'exécution sommaire par les Allemands lors de la débâcle est évoquée par Garnier, n'aurait-il pas été préférable de rappeler ce que disent les travaux les plus récents sur ce point, des publications d'Armelle Mabon qui évoque notamment le cas de ces prisonniers noirs restés en Bretagne jusqu'en 1944 (Prisonniers de guerre indigènes. Visages oubliés de la France occupée, Paris, La Découverte, 2010) - à celles de Raffael Scheck (Une saison noire. Les massacres de tirailleurs sénégalais, mai-juin 1940, Paris, Tallandier, 2007)?

Et il en va de même de nombreux points, sur lesquels l'on aurait aimé que le lecteur soit éclairé quant à la banalité - ou pas - de ce que traduisent les dessins ou les lettres : du travail dans les Kommandos à la place du théâtre - bien mise en évidence dès l'entre-deux-guerres par la Grande Illusion, le film de Jean Renoir -, des relations avec les gardiens à la mise en récit par Garnier de ses hésitations face aux possibilités d'évasion qui se présentent à lui, pour n'en rester qu'à ces quelques exemples.

On l'aura compris : alors que de nouveaux médias permettent de saisir autrement l'expérience de la captivité entre 1940 et 1945 - l'on pense, entre autres, aux excellents albums BD de Jacques Tardi, Moi René Tardi, prisonnier de guerre au Stalag II B (Paris, Casterman, 2012), ou de Florent Silloray, Le carnet de Roger (Paris, Sarbacane, 2011), consacré dans ce dernier cas à son grand-père, un autre prisonnier breton, originaire de Nantes celui-là -, il nous semble que les dessins de François Garnier auraient mérité plus d'égards, plus encore dans une collection universitaire.

Yann LAGADEC

Bour, Julie, Gueit-Montchal, Lydiane, Dard, Olivier, Richard, Gilles (dir.), Louis Jacquinot, un indépendant en politique, Presses de l'université ParisSorbonne, 2013, 2008 p.

En dehors de la Meuse, département dont il a été député de 1932 à 1973 et président du Conseil général de 1945 à 1973, qui connaît encore Louis Jacquinot (1898-1993)? C'est pour rendre hommage à l'homme politique meusien mais aussi à l'ancien ministre sous trois Républiques qu'avec l'appui du Conseil général de la Meuse, les Archives départementales et le Centre de recherche universitaire lorrain d'histoire dirigé par Olivier Dard de l'université de Metz ont organisé en 2011 un colloque scientifique sur la carrière de Louis Jacquinot. Ce travail initié par Julie Bour a pu s'appuyer sur les fonds d'hommes politiques déposés aux archives départementales et présentés par leur directrice Lydiane Gueit-Montchal. En effet, ce fonds possède une très riche collection de photographies déposée par Louis Jacquinot 